\title{
Multi-Objective Optimisation of Biodiesel Synthesis in Simulated Moving Bed Reactor
}

\author{
Nillohit Mitra Ray and Ajay K. Ray *(D) \\ Department of Chemical and Biochemical Engineering, University of Western Ontario, \\ London, ON N6A 3K7, Canada; nmitrara@uwo.ca \\ * Correspondence: aray6@uwo.ca; Fax: +1-519-661-3498
}

Citation: Ray, N.M.; Ray, A.K. Multi-Objective Optimisation of Biodiesel Synthesis in Simulated Moving Bed Reactor. Separations 2021, 8, 127. https://doi.org/10.3390/ separations 8080127

Academic Editor: Sascha Nowak

Received: 29 June 2021

Accepted: 17 August 2021

Published: 21 August 2021

Publisher's Note: MDPI stays neutral with regard to jurisdictional claims in published maps and institutional affiliations.

Copyright: (C) 2021 by the authors Licensee MDPI, Basel, Switzerland. This article is an open access article distributed under the terms and conditions of the Creative Commons Attribution (CC BY) license (https:/ / creativecommons.org/licenses/by/ $4.0 /)$.

\begin{abstract}
In this work, multi-objective optimisation study was performed to determine the performance improvement in a simulated moving bed reactor (SMBR) for biodiesel synthesis. The selection of the operating parameters such as switching time, liquid flow rates in various sections, as well as the length and number of columns is not straightforward in an SMBR. In most cases, conflicting requirements and constraints influence the optimal selection of the decision (operating or design) variables. A mathematical model that predicts single-column experimental results well was modified and verified experimentally for multiple-column SMBR system. In this article, a few multi-objective optimisation problems were carried out for both existing set-up as well as at the design stage. A non-dominated sorting genetic algorithm (NSGA) was used as the optimisation tool for the optimisation study. Due to conflicting effect of process parameters, the multi-objective optimisation study resulted in non-dominated Pareto optimal solutions. It was shown that significant increase in yield and purity of biodiesel in SMBR was possible both for operating and at design stage.
\end{abstract}

Keywords: multifunctional reactor; reactive separation; multi-objective optimization; chromatographic reactor; biodiesel synthesis; multi-column chromatography; simulated moving bed

\section{Introduction}

The simulated moving bed (SMB) technology has gained considerable interest for a wide variety of applications [1]. It is an adsorption-based chromatographic separation process in which the counter-current movement of the mobile phase with respect to stationary phase is simulated by periodic switching of the introduction and withdrawal ports along a series of columns. This technology has been successfully used to achieve higher yield in case of equilibrium-limited reversible reactions in which it helps to push the equilibrium forward by in situ separation of the products as soon they are formed [2]. However, the SMB process is complex to implement.

Various operating parameters such as switching time, flow rates in each section, length of columns, etc., must be appropriately (if possible, optimally) selected for successful and efficient operation. Hence, systematic optimisation of SMBR is necessary for its industrial implementation and to make it economically viable [3].

$$
\begin{aligned}
& \mathrm{R}-\mathrm{COOH}+\mathrm{R}^{\prime}-\mathrm{OH} \Leftrightarrow \mathrm{R}-\mathrm{COOR}^{\prime}+\mathrm{H}_{2} \mathrm{O} \\
& \text { (Acid) (Alcohol) (Biodiesel) (Water) }
\end{aligned}
$$

The modelling, simulation and experimental study of SMBR for biodiesel synthesis have been carried out and reported earlier [4]. The reaction investigated is given by Equation (1).

The free fatty acid used was oleic acid, alcohol used was methanol and fatty acid ester obtained was methyl oleate, which is biodiesel. A mathematical model was used to describe the dynamic behaviour of SMBR. The model was validated by carrying out experiments at different conditions and comparing the experimental results with the model 
predicted values [4]. It was observed that the model predicted the experiments reasonably well [4]. Thereafter, a parametric sensitivity study was carried out to determine the effect of various operating parameters on the functioning of SMBR. It was found out that there is a complex interplay between the various operating parameters such as switching time, the feed, desorbent and raffinate flow rates. Together, they collectively influence the yield and purity of biodiesel in SMBR. Sensitivity studies showed that although some parameters influence yield and purity in conflicting manner, it is possible to further improve the yield and purity of biodiesel in a SMBR, if systematic optimisation is performed to determine an optimal set of the operating parameters. To determine these best (optimal) set of values, a methodical multi-objective optimisation study of the SMBR needs to be done. In this study, multi-objective optimisation of the SMBR for biodiesel synthesis was carried out for different sets of objective functions.

\section{Multi-Objective Optimisation}

The optimisation of a chemical process has been an interesting field of study for quite some time. Most researchers solve optimisation problems that involve single objective function. Usually, this single objective accounted for only cost and/or economic efficiency of the process, which is a scalar quantity. But real world (chemical) engineering problems often involve a variety of factors that requires multiple objectives to fulfil simultaneously. For example, yield, purity, selectivity, solvent consumption as well as variables such as reliability, safety, quality control, etc., which cannot be easily compared to each other. Hence, very often they cannot be scalarised into a single, meaningful objective function. Until a few years ago, this scalarisation was done by assigning some weightage to all the factors involved. But this was not a practical approach, as in real world the various factors do not equally affect a process. As a result, the solution obtained from such optimisation was largely dependent on the weightage assigned to the various factors. Moreover, if the objective function is non-convex, it gave rise to a duality gap because of which optimisation algorithm misses some optimal solutions which can never be found regardless of the weighting factors chosen [5]. Furthermore, a single objective function defined as cost or profit results in solution that is time-specific and site-specific. The optimal value based on cost of raw material or revenue generated from products differed from region-to-region and year-to-year. Hence, reported results based on cost or profit cannot be used judiciously at different region and at different time. However, one can calculate cost or profit at any location and at any time that is best suited for profitable operation if the optimisation study is done using real variables such as conversion, yield, selectivity, etc., [6].

Optimisation of multiple criteria simultaneously considers several objectives together, even when they are conflicting in nature. In case of conflicting effect, instead of finding the best possible single unique global solution, a set of equally good non-dominated solutions are obtained. These are known as Pareto optimal solutions. In such a set, no one solution can be considered superior to other with respect to all objective functions. As one moves from one optimal solution to another, it results in improvement of at least one objective function and deterioration of at least another objective function. Hence, an operator must select, one solution according to priority. In recent years, multi-objective optimisation has gained popularity for solving problems in various aspects of chemical engineering [7-20]. It has also been used for both reactive and separative SMB processes [21-30].

\section{Optimisation Methodology}

In this work, Genetic Algorithm (GA), a non-traditional search and optimisation method that has become quite popular in engineering optimisation has been used. GA mimics the principles of genetics and the Darwinian principle of natural selection (i.e., survival of the fittest). A simple genetic algorithm (SGA) is suitable for optimising problems with a single-objective function. In single-objective function optimisation, one attempts to find the best solution, which is usually the global minimum (or maximum). However, most real-world problems involve the simultaneous optimisation of multiple objective func- 
tions (a vector). Such problems are conceptually different from single-objective-function problems. In multiple objective-function optimisations, a solution that is the best (global optimum) with respect to all objectives might not exist due to conflicting effect of one or more decision variables on objective functions. Instead, an entire set of optimal solutions may exist that are equally good. These solutions are known as (non-dominated) Pareto-optimal solutions. A Pareto set, for example, for a two-objective-function problem is described by a set of points such that, when one moves from one point to any other, one objective function improves while the other worsens. Thus, one cannot say that any one of these points is superior (or dominant) to any other. Because none of the non-dominated solutions in the Pareto set is superior to any other, any one of them is an acceptable solution. The choice of one solution over another requires additional knowledge of the problem, and often, this knowledge is intuitive and non-quantifiable. There are various approaches available for solving a multi-objective optimisation problem: The goal attainment method, the $\varepsilon$ constraint method and the Non-Dominated Sorting Genetic Algorithm (NSGA) method. In this work, the NGSA method has been used to carry out the optimisation process to obtain the Pareto optimal set [31,32].

The Genetic Algorithm method is a search technique developed by Holland [33] in 1975. It imitates the process of natural selection and natural genetics. In this technique, the decision variables are coded into a set of binary strings or numbers, known as chromosomes, thereby creating a 'population (gene pool)' of such binary strings. These chromosomes are generated using random number generators. Each chromosome is then mapped into a set of real values of the decision variables using an upper and lower bound for each of these decision variables. When all the chromosomes are allocated, the process model is used to assign a value of the objective function that reflects its 'fitness' value. In this way, a 'gene pool' of chromosomes is created, with the value of the objective function of each chromosome representing its 'fitness' value. The Darwinian principle of 'survival of the fittest' is then used to create a new and improved gene pool (new generation). This is done by preparing a 'mating pool' that comprises copies of chromosomes, the number of copies of any chromosome being proportional to its fitness based on Darwin's principle of 'survival of the fittest'. After this, pairs of chromosomes are randomly selected and 'mated' using operations like those in genetic reproduction so that information exchange takes place between them, giving rise to daughter chromosomes. This gives rise to a new and improved gene pool with 'fitness' value better than the previous one. This process is repeated over several generations to get a more improved gene pool. The process goes on until the chromosomes match the criteria assigned by the objective functions [34].

The genetic algorithm is robust and superior to many traditional optimisation algorithms. It has a number of advantages: (a) Efficient handling of uncertainty problems, stochasticity's and discrete search spaces; (b) its efficiency has little effect on the shape and 'spread' of the Pareto optimal front, unlike other techniques where efficiency of the technique determines the spread of the solution obtained; and (c) an entire Pareto set can be obtained in a single application, unlike other techniques like the $\varepsilon$-constraint method where the technique must be applied over and over again to generate a Pareto front. Several versions of the genetic algorithm have been used to solve problems in chemical and reaction engineering. In this work, the NSGA II has been used to optimise the synthesis of biodiesel in the SMBR [31].

\section{Mathematical Model for Synthesis of Biodiesel in SMBR}

Figure 1 shows a schematic diagram of SMBR and the principle of its operation. It consists of several columns of uniform cross-section, each of length $L$ and packed with the ion-exchange resin, which acts as both catalyst and adsorbent. The columns are connected in series in a circular array. Two incoming fluid streams (feed and eluent/desorbent) and two outgoing fluid streams (extract and raffinate) divide the reactor system into four sections ( $P, Q, R$ and $S)$, with $p, q, r$ and s number of columns in each section respectively, as illustrated in Figure 1. $Q_{p}$, the flow rate in section $P$, is regarded as the reference flow rate, to 
which all other flow rates are described. If $\alpha, \beta$ and $\gamma$ are assumed to be the ratio of feed flow rate $(F)$, raffinate flow rate $(R)$ and desorbent flow rate (D) respectively, to the reference flow rate, $Q_{p}$, then flow rates in each section can be defined as shown in Figure 1. Simulation of counter-current movement of the solid is achieved by advancing the inlet and withdrawal ports, column by column, in the same direction of the fluid flow, at a predetermined switching time, $t_{s}$. During a switch, these ports move simultaneously by one column, in the direction of the flow of mobile phase. To achieve separation between the components, the internal flow rates of the fluid phases within the four sections, and the switching time (which defines the hypothetical solid phase velocity) must be specified appropriately. By suitable selection of switching time, counter-current or co-current movement of the solid phase with respect to the fluid phase can be achieved in each section. Petroulas and co-workers [35] defined for true counter-current moving bed chromatographic reactor (CMCR) a parameter, $\sigma_{i}$, called relative carrying capacity of the solid relative to the fluid stream for any component $i$ as:

$$
\sigma_{i}=\left[\frac{1-\epsilon}{\varepsilon}\right] N K_{i} \frac{u_{s}}{u_{g}}=\delta_{i} \frac{u_{s}}{u_{g}}
$$

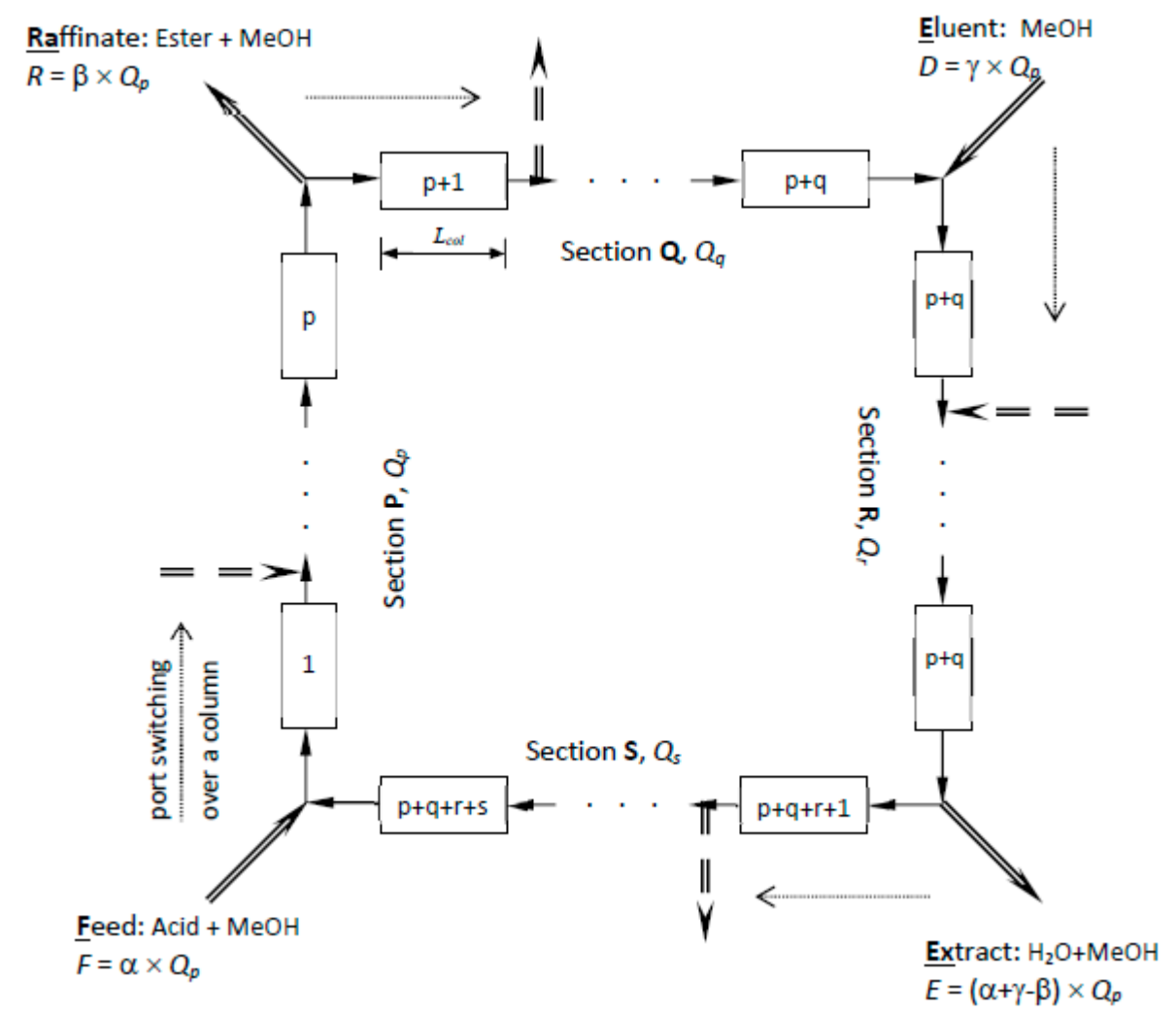

Figure 1. Schematic flow diagram of the SMBR. The inlets and outlets divide the entire system into four section, $\mathrm{P}, \mathrm{Q}, \mathrm{R}$ and $\mathrm{S}$ with respectively $\mathrm{p}, \mathrm{q}, \mathrm{r}$ and $\mathrm{s}$ number of columns. The flow retes in each section is given by $Q q=(1-\beta) Q q, Q r=(1-\beta+\gamma) Q p$, $Q s=(1-\alpha) Q p$, where $\alpha, \beta$ and $\gamma$ are given by $F / Q p, R a / Q p, E / Q p$.

They showed that to achieve counter-current separation between two components, one must set $\sigma$ greater than 1 for one and less than 1 for the other. Fish and co-workers [36] defined $V i$, the net velocity at which component $i$ travels (or the concentration front moves) within the column, which for linear isotherm is given by:

$$
V_{i}=u_{g}\left[\frac{1-\sigma_{i}}{1+\delta_{i}}\right]
$$


Therefore, when $\sigma_{i}<1, V_{i}>0$ (species move with the fluid phase), and when $\sigma_{i}>1$, $V_{i}<0$ (species move with the solid phase). When $\sigma=0$, it represents fixed bed. Ray and co-workers [37] re-defined the above parameter, $\sigma$, for SMBR by replacing the solid-phase velocity, us, in CMCR by a hypothetical solid phase velocity, $\zeta$, defined as $\zeta=\mathrm{L} / t_{s}$ for SMBR. They found, both theoretically [1] and experimentally [2], that simulation of the counter-current movement between two components can be achieved when re-defined $\sigma^{\prime}$ s were set such that it is greater than 1 for one and less than 1 for the other component. Hence, in the present study if we set $\sigma$ appropriately, the more strongly adsorbed component (H2O) will move with the solid (resin) stream and could be collected the extract port, while at the same time the less strongly adsorbed component (biodiesel) will travel with the fluid stream and could be collected at the raffinate port. It should also be noted that the parameter $\sigma$ defined by the research group of Carr and Aris [35] is similar to $\beta$ defined by the research group of Hashimoto [38], $\gamma$ defined by the research group of Ruthven [39] and $\mathrm{m}$ defined by the research group of Morbidelli [40].

The material balance of the SMBR is based on the equilibrium dispersive model which is as follows:

$$
\frac{\partial C_{i j}^{(N)}}{\partial t}+\left[\frac{1-\epsilon}{\varepsilon}\right] \frac{\partial q_{i j}^{(N)}}{\partial t}+\frac{u_{\varnothing}}{\varepsilon} \frac{\partial C_{i j}^{(N)}}{\partial z}-\left[\frac{1-\epsilon}{\varepsilon}\right] \vartheta_{i} R_{j}^{(N)}=D_{i k} \frac{\partial^{2} C_{i j}^{(N)}}{\partial z^{2}}
$$

where $C_{i}$ is the concentration of component $i$ in the mobile phase (mol/L), $\mathrm{t}$ is the time (s), $q_{i}$ is the concentration of component $i$ in the polymer phase (mol/L), $\varepsilon$ is the column void fraction $(-), u$ is the superficial fluid phase flow rate $(\mathrm{m} / \mathrm{s}), z$ is the axial coordinate (m), $v_{i}$ is the stoichiometric coefficient of the component $i, \mathrm{R}$ is the reaction rate and $D_{i}$ is the apparent dispersion coefficient of the component $\mathrm{i}\left(\mathrm{m}^{2} / \mathrm{s}\right)$. For the component $i$ in the $j$ th column during the $N$ th switching period, $u_{\varnothing}$ denotes superficial flow rate in section $\phi$ (where $\phi=\mathrm{P}, \mathrm{Q}, \mathrm{R}, \mathrm{S}$ ) and the reaction rate expressions and adsorption isotherms are given by

$$
\begin{gathered}
R_{j}^{(N)}=k_{f s}\left[q_{f a, j}^{(N)}-\frac{q_{m e, j}^{(N)} q_{w, j}^{(N)}}{K_{e q}}\right] \\
q_{i j}^{(N)}=K_{i} C_{i j}^{(N)}
\end{gathered}
$$

The initial and boundary conditions are Initial conditions

When $\mathrm{N}=0$,

$$
C_{i j}^{(0)}=C_{i j}^{(\text {initial })}=0
$$

When $\mathrm{N} \geq 1$,

$$
\begin{gathered}
C_{i j}^{(N)}=C_{i, j+1}^{(N-1)} \text { for } j=1 \sim\left(N_{c o l}-1\right) \\
C_{i j}^{(N)}=C_{i, 1}^{(N-1)} \text { for } j=N_{c o l}
\end{gathered}
$$

Boundary conditions

Feed entry point

$$
\left.C_{i j}^{(N)}\right|_{z=0}=\left.(1-\alpha) C_{i, N c o l}^{(N)}\right|_{z=L}+\alpha C_{i, f}
$$

Raffinate take-off point

$$
\left.C_{i, p+1}^{(N)}\right|_{z=0}=\left.C_{i, p}^{(N)}\right|_{z=L}
$$


Eluent inlet point

$$
\left.C_{i, p+q+1}^{(N)}\right|_{z=0}=\left.\left[\frac{1-\beta}{1-\beta+\gamma}\right] C_{i, p+q}^{(N)}\right|_{z=L}
$$

Extract take off point

$$
\left.C_{i, p+q+r+1}^{(N)}\right|_{z=0}=\left.C_{i, p+q+r}^{(N)}\right|_{z=L}
$$

The mass balance equation (Equation (4)), initial and boundary conditions (Equations (7) and (8) respectively), reaction kinetic equation (Equation (5)) and adsorption isotherm (Equation (6)) completely define the SMBR system. The partial differential equations were solved using method of lines. They were first discretised using finite difference method to convert it into a set of several coupled ordinary differential equation of initial value problems (ODE-IVP) and the resultant stiff ODEs were solved using the DIVPAG subroutine (which is based on Gear's method) in the IMSL library. Due to the presence of periodic switching in the system, whenever a switching is performed, a new IVP must be solved. Eventually, a periodic steady state with a period equal to the switching time is attained. After each switching, the column numbering is redefined as follows:

$$
\begin{gathered}
\text { Before switching After Switcing } \\
\text { Column } 1 \text { Column } \mathrm{N}_{\text {col }} \\
\text { Column } \mathrm{j} \text { Column } \mathrm{j}-1, \mathrm{j}=1,2,3, \ldots, \mathrm{N}_{\text {col }}
\end{gathered}
$$

The model can also predict the concentration profiles of the reactant and products. It was observed that the SMBR reached the pseudo-steady state after about 20 switching operations. Improved yield and purity of biodiesel was achieved due to reaction and in-situ separation of products in the system. The time taken for one simulation run to achieve the cyclic steady state for SMBR was about $4 \mathrm{~s}$ in a computer equipped with Intel Pentium Core 2 Duo CPU.

The design of the SMBR and the operating conditions to be used therein is set such that the yield and purity of biodiesel are maximised. The yield and purity are defined in this work as follows:

(1) Yield of methyl ester $\left(Y_{M E}\right)$ -

$$
Y_{M E}=\frac{\text { methyl oleate collected in raffinate }}{\text { oleic acid fed }}=\frac{\beta \cdot\left[\left.\int_{0}^{t_{s}} C_{M E, p}^{(N)}\right|_{z=L_{c o l}} d t\right]}{\alpha \cdot C_{F A, f . t_{s}}}
$$

(2) Purity of methyl ester $\left(P_{M E}\right)-$

$$
\begin{array}{r}
P_{M E}=\frac{\text { methyl oleate collected in raffinate }}{\text { oleic acid +water+methyl oleate collected in raffinate }} \\
=\frac{\left.\int_{0}^{t_{s}} C_{M E, p}^{(N)}\right|_{z=L_{c o l}} d t}{\left.\int_{0}^{t_{s}}\left(C_{M E, p}^{(N)}+C_{W, p}^{(N)}+C_{F A, p}^{(N)}\right)\right|_{z=L_{c o l}} d t}
\end{array}
$$

As described earlier, the mathematical model was validated with experimental results [4]. The model was subsequently checked for robustness through a parametric sensitivity study. It was determined that improved yield and purity were possible if the various operating parameters were optimised. Moreover, some decision variables found to be influencing the yield and purity value in conflicting manner. Hence, a multi-objective optimisation of the SMBR is carried out which is expected to result in non-dominated equally good Pareto optimal solutions. 


\section{Optimisation of Biodiesel Production in SMBR}

In the open literature, many investigations of SMBRs can be found, but there are still no reported industrial application of this technology, probably because of the complexity of the process and the absence of any general guidelines for the design of the process. Most of the design approaches are not based on systematic and rigorous mathematical optimisation methods. In recent years, an extremely robust technique, the genetic algorithm (GA) as well as its adaptations for more useful but complex multi-objective optimisation problems, has become popular. GA-based approaches do not require any initial guesses and converge to the global optimum even when several local optima are present. GA uses a population of several points (solutions) and works with probabilistic (rather than deterministic) operators. In addition, GA uses information on the objective function and not its derivatives.

In this article, the multi-objective optimisation of the complex chemical processes involved in a simulated moving-bed reactor (SMBR) for biodiesel synthesis is reported. For the proper design of a SMBR, and more importantly, for an understanding of the principles of operation of a SMBR, a multi-objective optimisation study is much more meaningful. To the best of our knowledge, this is the first attempt at a multi-objective optimisation study of simulated moving-bed reactor systems for biodiesel production.

Different objectives can be used for optimisation of reactive SMB. One can select objectives that are economical (like profit, production cost), safety, environmental impact, thermodynamic and/or operational (like yield, productivity). Moreover, optimisation formulation can be categorised into two approaches: (a) Existing stage optimisation: This involves optimisation of the existing set-up in which one does not have the freedom to select length, diameter or number of columns in the system. The process variables that can be used as decision variables are switching time and flow rates in different sections. Objectives which can be considered for this problem are maximisation of yield and purity of biodiesel, which are related to increasing quality of the product, or minimisation of desorbent flow rate, which is related to the operating cost of the system. (b) Design stage optimisation: This involves performance enhancement by altering the design parameters of the unit such as length, diameter as well as number of columns as decision variables in addition to the other operating variables. The objective functions can be same as that of the existing-stage optimisation.

For biodiesel production in reactive SMBR, the product of interest is methyl ester which is obtained at the raffinate port. Hence, one can consider objective functions such as maximisation of the product quality (yield and/or purity of the product at the raffinate port) or conversion of the limiting reactant. One can also consider minimisation of desorbent consumption as an objective function. All these objective functions can be considered together, but that gives rise to complexity in analysing the optimum solutions. For example, if we want to simultaneously optimise three objectives, non-dominated Pareto optimal solutions could also include deterioration of two objective functions and improvement of the third, or vice versa. This will give rise to multi-dimensional solutions, which are difficult to analyse as optimal solutions lie on 3-dimensional surfaces. Moreover, with large number of objective functions, the search space will be limited. Hence, in this work, only two objective functions are considered at any time. Production of high-quality biodiesel is of paramount importance for their use in engines [41,42]. Therefore, maximisation of purity is considered one objective function in all the optimisation problems considered.

For this work, a four column SMBR setup was used, with one column in each section. Both existing stage and design stage optimisation problems were considered. The various decision variables involved were: process parameter (switching time, $t_{s}$ ); throughput parameters (feed flow rate, $\alpha$ and/or raffinate flow rate, $\beta$ ); and operating cost parameters (eluent flow rate, $\gamma$ and flow rate in section $P, Q P$, which is related to the pressure drop in the system). For the design-stage optimisation, an additional parameter, length of the column $\mathrm{L}_{\mathrm{col}}$, was used. Table 1 represents the optimisation problems studied in this work. 
Table 1. Optimisation problems along with their objective functions, constraints, decision variables and fixed parameters.

\begin{tabular}{|c|c|c|c|c|}
\hline Case & Objective Functions & Constraints & Decision Variables & Fixed Parameters \\
\hline 1.1 Existing setup & $\begin{array}{l}\text { Maximum } Y_{M E} \\
\text { Maximum } P_{M E}\end{array}$ & $\begin{array}{l}Y_{M E} \geq 50 \% \\
P_{M E} \geq 50 \%\end{array}$ & $\begin{array}{c}1 \leq t_{s} \leq 17(\mathrm{~min}) \\
0.1 \leq \beta \leq 1 \\
1 \leq \gamma \leq 5\end{array}$ & $\begin{array}{c}Q_{P}=1.66 \mathrm{ml} / \mathrm{min} \\
\alpha=0.1 \\
{[\mathrm{~F}]=0.21 \mathrm{~mol} / \mathrm{lit}} \\
\mathrm{L}_{\mathrm{col}}=25 \mathrm{~cm}, \mathrm{~N}_{\mathrm{col}}=4\end{array}$ \\
\hline 1.2 Existing setup & $\begin{array}{l}\text { Maximum } P_{M E} \\
\text { Minimum } \gamma\end{array}$ & $\begin{array}{l}Y_{M E} \geq 50 \% \\
P_{M E} \geq 50 \%\end{array}$ & Same as Case 1.1 & Same as Case 1.1 \\
\hline 2.1 Design stage & $\begin{array}{l}\text { Maximum } Y_{M E} \\
\text { Maximum } P_{M E}\end{array}$ & $\begin{array}{l}Y_{M E} \geq 50 \% \\
P_{M E} \geq 50 \%\end{array}$ & $\begin{array}{c}\text { Same as } \\
\text { Case } 1.1 \\
0.2 \leq \mathrm{L}_{\mathrm{col}} \leq 0.5(\mathrm{~m})\end{array}$ & $\begin{array}{c}\text { Same as Case } 1.1 \text { except } \\
\mathrm{L}_{\mathrm{col}} \text { is not fixed }\end{array}$ \\
\hline 2.2 Design stage & $\begin{array}{l}\text { Maximum } P_{M E} \\
\text { Minimum } \gamma\end{array}$ & $\begin{array}{l}Y_{M E} \geq 50 \% \\
P_{M E} \geq 50 \%\end{array}$ & $\begin{array}{l}\text { Same as } \\
\text { Case } 2.1\end{array}$ & Same as Case 2.1 \\
\hline
\end{tabular}

The Pareto optimal solutions were generated using NSGA-II. 50 chromosomes (solutions) along with 50 generations (iterations) were considered for obtaining converged Pareto set. Table 2 represents the numerical parameter values used in NSGA II for all the optimisation runs. The time taken for one optimisation run (50 solutions for 50 generations) consisting of 2500 simulation runs was about $7 \mathrm{~h}$ of clock time in a computer equipped with Intel Pentium Core 2 Duo CPU.

Table 2. Numerical parameter values used in NSGA optimisation.

\begin{tabular}{cc}
\hline Number of generations, $\mathrm{N}_{\text {gen }}$ & 50 \\
Population size, $\mathrm{P}_{\text {pop }}$ & 50 \\
Probability of crossover, $\mathrm{P}_{\text {cross }}$ & 0.65 \\
Probability of mutation, $\mathrm{P}_{\text {mute }}$ & 0.002 \\
Spreading parameter, $\sigma$ & 0.075 \\
Sharing function exponent, $\alpha$ & 2.0 \\
Random number generator seed, $\mathrm{S}_{\mathrm{r}}$ & 0.455 \\
\hline
\end{tabular}

\section{Optimisation of Existing Setup}

The first two multi-objective optimisation problems solved were for an existing set-up. In case 1.1, the objective of this problem is to achieve simultaneous maximisation of yield and purity. Figure 2 represents the Pareto optimal solutions for this optimisation problem and the influence of the decision variables on the Pareto set. Some of the decision variables act on yield and purity in a conflicting manner. A yield of about $79 \%$ can be obtained but the maximum purity possible at that yield is $76 \%$. Whereas increasing the purity to $87 \%$ reduces the maximum possible yield to about $72 \%$. The purity level is also very sensitive to raffinate flow rate $(\beta)$, as is clear from the figure; decreasing $\beta$ below 0.26 results in an increase in purity, with about $87 \%$ purity being achieved at $\beta \approx 0.22$. This happens because increasing the raffinate flow rate decreases the residence time within the column, thus reducing the conversion of the reactant (oleic acid) to biodiesel. Hence, lower raffinate flow rate is required to increase the residence time and purity. As far as optimum switching time is concerned, it seems to remain constant at around $5 \mathrm{~min}$, indicating it is not affected for achieving high or low purity value. In case of desorbent flow rate, the purity seems to linearly increase when $\gamma$ increases from 1 to 2 , but further increase of $\gamma$ does not significantly affect purity. Hence, at high desorbent flow rates, purity is not affected. This is because when the desorbent flow rate is set above a minimum threshold, complete regeneration of column occurs before a switch; its further increase does not matter thereafter. One should note that the optimal Pareto set presented are nearly converged solution as to get smooth Pareto curve (global optimal Pareto set) one needs to run genetic algorithm for many generations with significant increase in computation time to get insignificant change in the Pareto curve. 

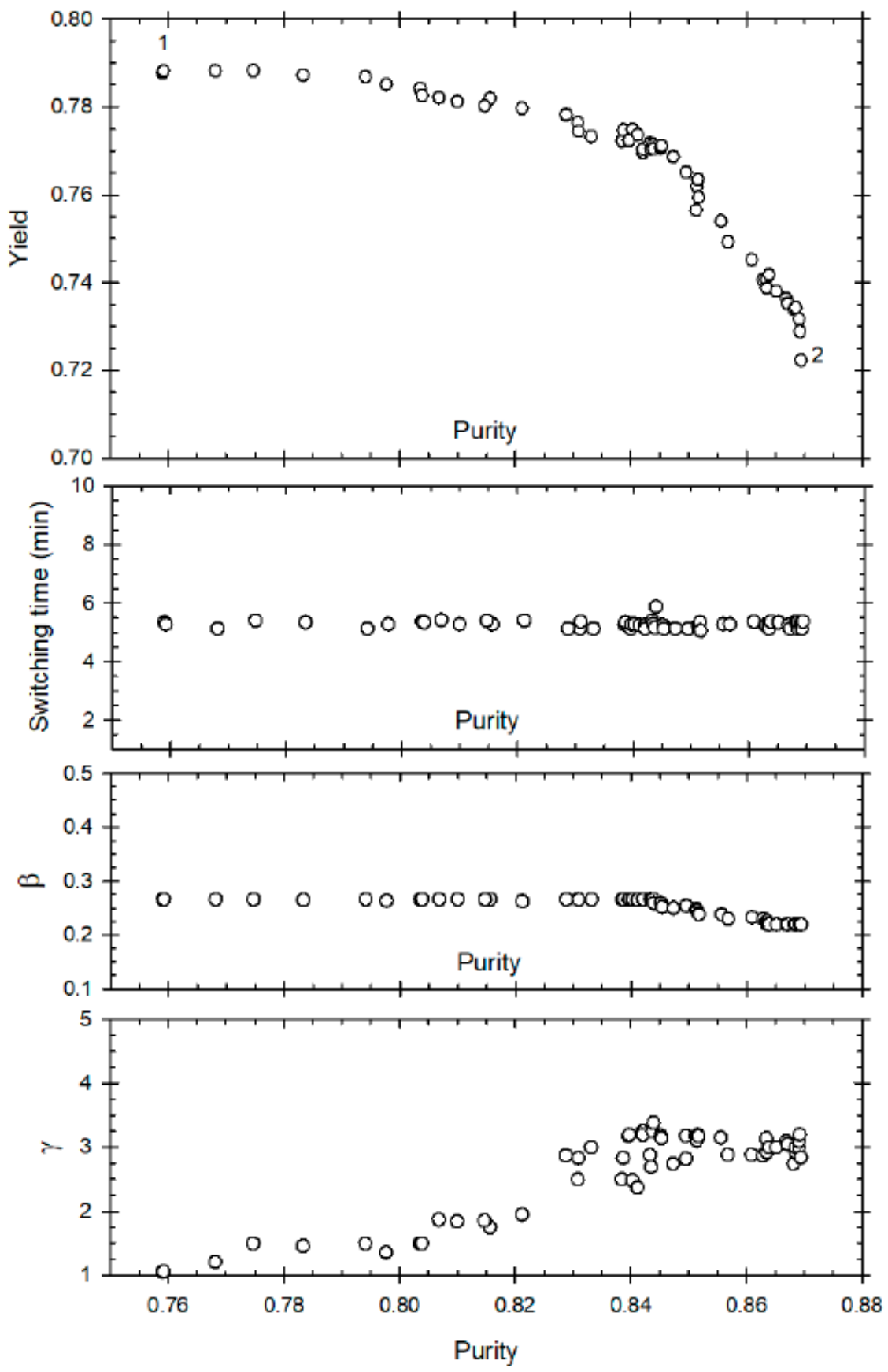

Figure 2. Existing set-up (Case 1.1 Maximization of Yield and Purity): Pareto optimal solutions and corresponding operating variables.

Figure 3 illustrates the steady state concentration profiles of the reactant and products in the column. Figure $3 a$ corresponds to point 1 and Figure $3 b$ corresponds to point 2 of Figure 2. It is evident that at point 1, water which is more strongly adsorbed breaks through the raffinate stream, thereby contaminating the desired product, methyl ester. Hence, purity of the product decreases. On the other hand, a high $\beta$ (raffinate flow) and low $\gamma$ (desorbent flow) results in presence of unreacted oleic acid, which gets recycled to section $\mathrm{P}$ at the end of a switch, resulting in higher yield. Point 2 corresponds to low raffinate flow rate and increased desorbent flow rate. At this condition, the residence time of the reactant in section P increases, resulting in higher conversion and increased product purity. Water is retained in section $\mathrm{P}$ and does not breakthrough in the raffinate stream. Moreover, complete regeneration of column occurs at high desorbent flow rate. However, 
this also means that unreacted oleic acid is washed out in the extract stream, and hence is not available for recycle after the next switch. Hence yield of the product decreases. According to this optimisation problem, the product purity is most significantly affected by $\beta$. Increasing $\gamma$ above a certain point does not affect the SMBR performance.
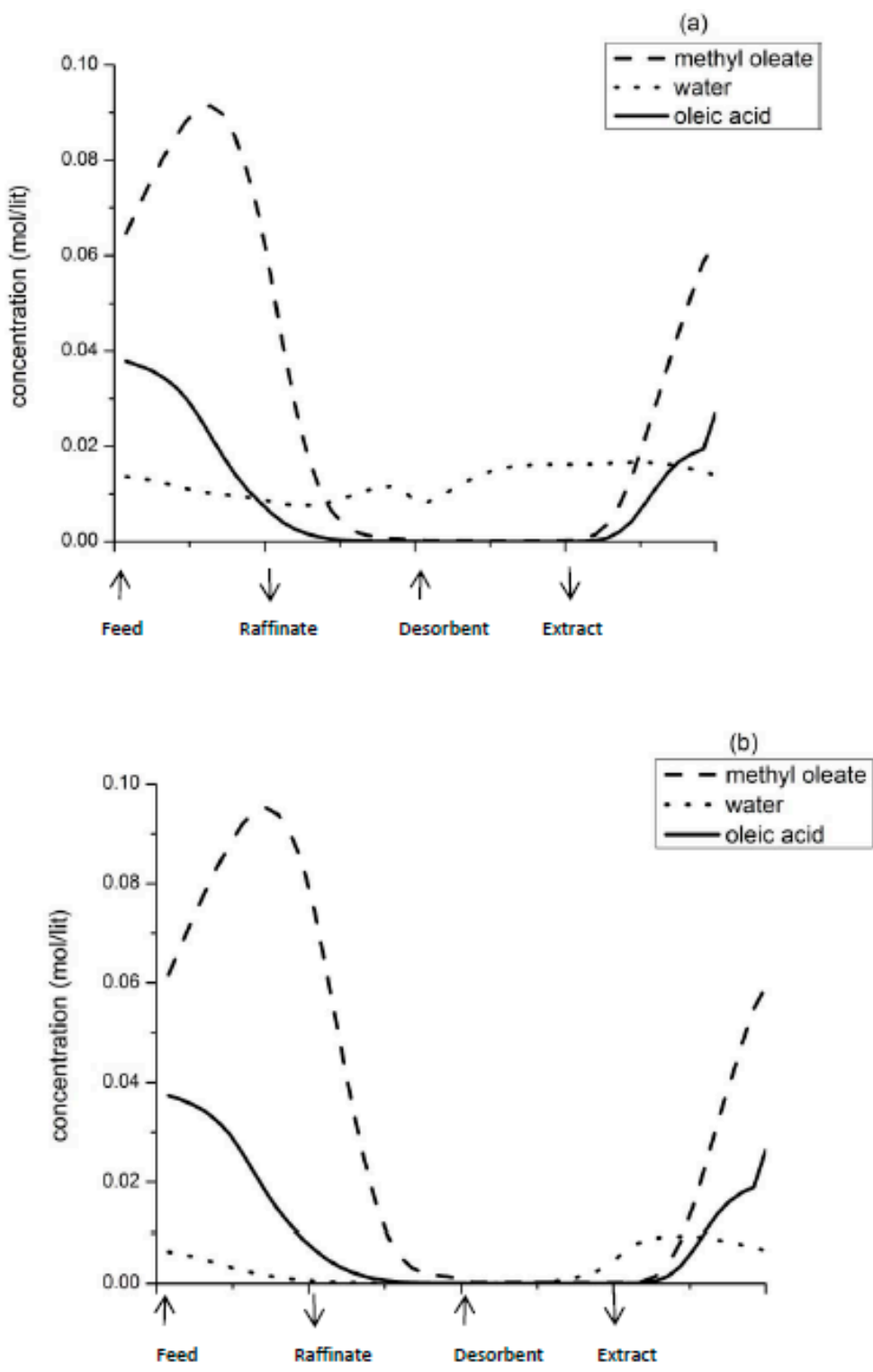

Figure 3. Steady state concentration profiles of methyl oleate-water-olenic acid system; (a) corresponding to point $1 \&(\mathbf{b})$ corresponding to point 2 of Figure 2.

Case 1.2: Maximisation of Purity and Minimisation of Desorbent Consumption

This optimisation problem attempts to minimise the operational cost by reducing the desorbent flow rate $(\gamma)$ along with maximizing purity of methyl ester. Figure 4 represents the Pareto set for desorbent consumption compared to product purity. At low values of $\gamma$, it has a linear correlation with $\mathrm{P}_{-} \mathrm{ME}$; increasing $\gamma$ from 1 to 1.5 results in an increase of purity from $80 \%$ to $87 \%$. However, after that even a slight increase in P_ME $(88 \%$ to $90 \%)$ results in exponential increase of $\gamma$ (1.5 to 3.5). Hence minimisation of desorbent consumption conflicts with improvement of purity. Note that it was not possible to achieve purity greater than $90.5 \%$ due to column efficiency (mass transfer limitation) of the packed material (resin) used in the study. Furthermore, note that higher purity is not restricted due to the range of the decision variables used as none of the decision variables reached the 
upper or lower bounds. The $\beta$ value is close to lower bound but not exactly at the lower bound.
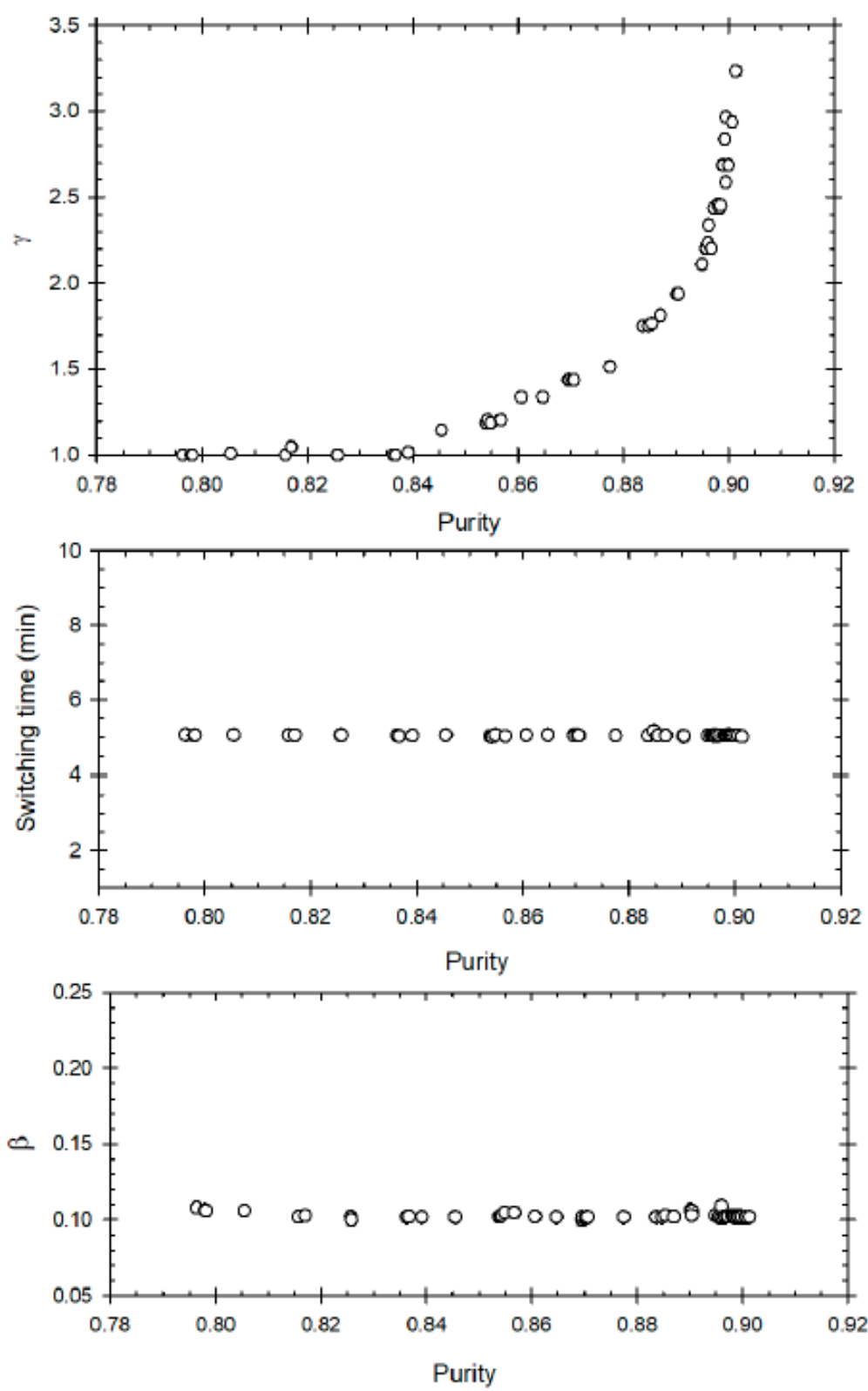

Figure 4. Case 1.2 Existing set-up. Maximization of Purity and minimization of Desorbent flow rate: Pareto optimal solutions and corresponding operating variables.

The switch time is relatively constant at around $5 \mathrm{~min}$, as is represented by Figure 4 . Figure 4 represents correlation between raffinate flow rate $(\beta)$ and P_ME. Unlike the previous optimisation problem, the purity is not significantly influenced by $\beta$ when one of the objectives is minimisation of $\gamma$. The only significant observation which can be made is that for high purity, a low value of $\beta$ (around 0.1) is desired. This is congruent with the fact that a low raffinate flow rate is required for increased residence time in section $\mathrm{P}$ of the SMBR to increase product purity. This optimisation problem results in the conclusion that when desorbent minimisation is one of the objective functions, then after a certain threshold value an exponential increase in $\gamma$ will result only in a slight improvement of purity. Hence to obtain high purity, $\gamma$ must be kept high just above the threshold value; a further increase is not required. 


\section{Design Stage Optimisation}

This problem involves optimisation of SMBR performance by allowing its design parameters such as length of the column to be selected optimally. It is worthwhile to consider this problem for industrial application. The parameter which has been considered for this is column length $\left(\mathrm{L}_{\mathrm{col}}\right)$. Two optimisation problems were once again considered for design-stage optimisation:

\subsection{Case 2.1 Simultaneous Maximisation of Yield and Purity}

The objective functions, constraints and decision variables for this problem are the same as those of Case 1.1, with the addition of another decision variable; column length $\left[0.2(\mathrm{~m}) \leq \mathrm{L}_{\mathrm{col}} \leq 0.5(\mathrm{~m})\right]$. The Pareto optimal solution is shown in Figure 5. Once again, it is observed that they act in conflicting manner. But a much higher value of purity $(97 \%)$ can be obtained as compared to case 1.1 where the highest purity value obtained was $87 \%$. Moreover, the highest yield value obtained in case 1.1 was $79 \%$ against a purity value of $76 \%$. The yield in this case is $90 \%$ corresponding to value of purity being marginally more than $90 \%$. Hence a drastic improvement is achieved when column length is introduced as a decision variable. The purity also acts in a conflicting manner against raffinate flow rate, as is evident from Figure 6 . A very low value of $\beta(\approx 0.1)$ is required to achieve $97 \%$ purity, indicating the requirement of a higher residence time in section P. Figure 6 represents that a high value of desorbent flow rate $(\gamma \approx 3.5)$ is required to achieve a purity in the range of $94 \%$ to $97 \%$. Just as in case 1.1, $\gamma$ must be kept above a threshold value; further increase in $\gamma$ will not improve purity. An increase in column length also improves purity, as represented by Figure 6. Larger column length means that the reactants will have more residence time, hence improving the conversion, purity and yield. As far as switch time is concerned, it has increased to about $11 \mathrm{~min}$ (see Figure 6) as compared to $5 \mathrm{~min}$ in Case 1.1. This is due to the introduction of column length as a decision variable. A higher $\mathrm{L}_{\mathrm{col}}$ value means indicates requirement of a higher residence time before a switch is made.

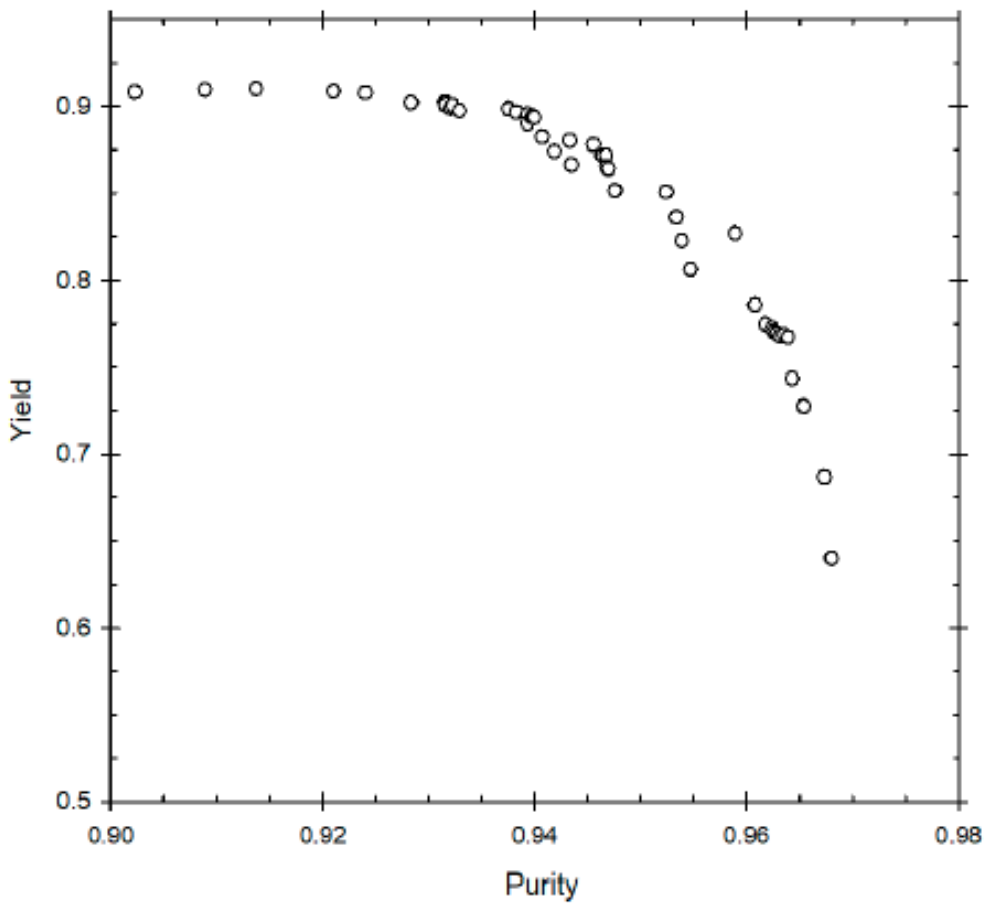

Figure 5. Design-stage optimization. Case 2.1 Maximization of Yield and Purity. 


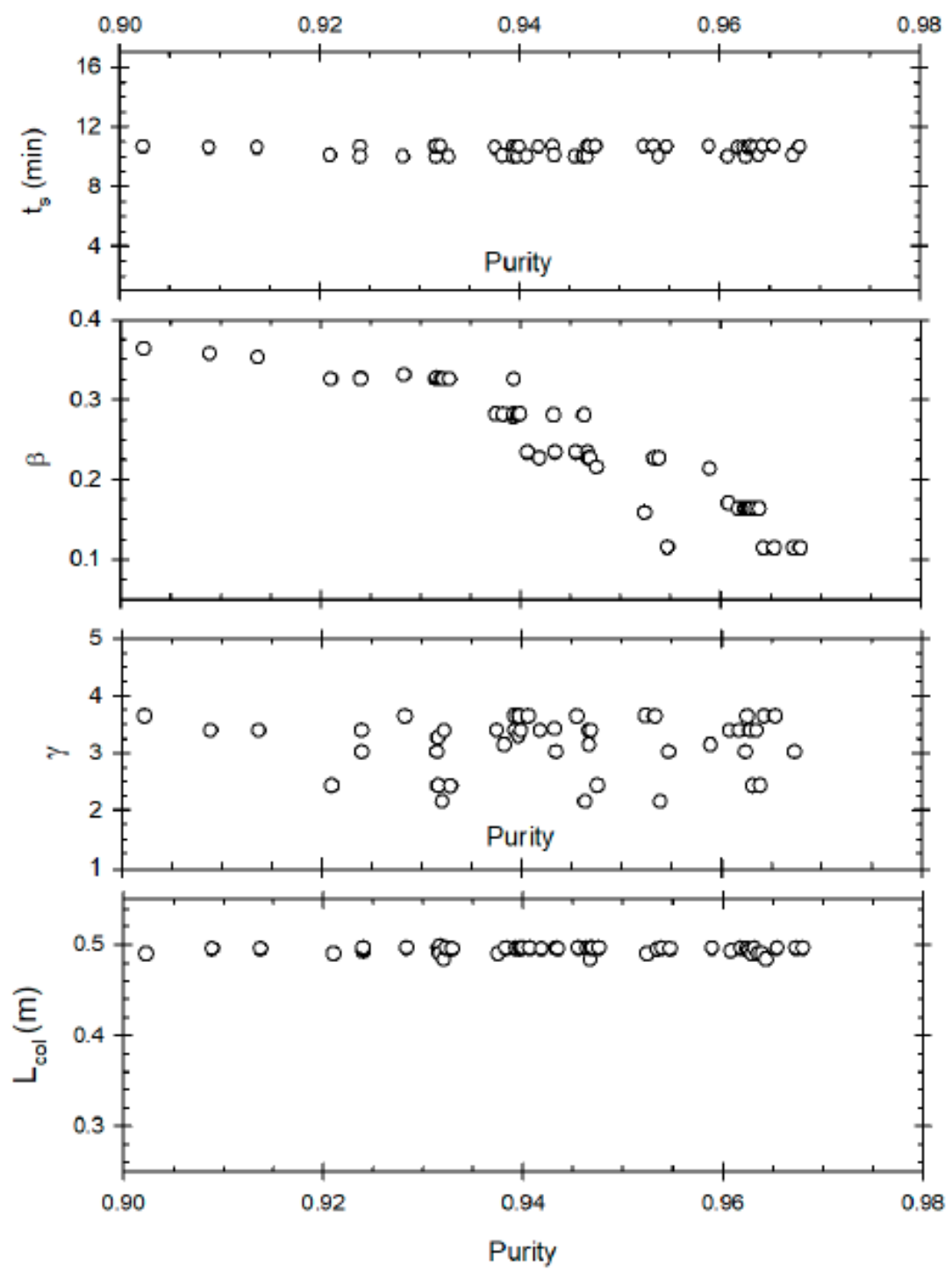

Figure 6. Case 2.1 Design-stage Optimization. Maximization of Yield and Purity. Corresponding operating variables for Pareto solutions shown in Figure 5.

One should note that desorbent flow rate $(\gamma)$ needs to be above a minimum threshold value for purging the column in section $\mathrm{R}$. Use of length as a decision variable, allows higher residence time with minimum $\beta$ value (as used in all other optimisation studies reported in this article) which results in higher purity that was obtained with existing-stage optimisation study. Note that $\gamma$ values are scattered as long as minimum threshold is attained and much higher purity cannot be achieved by increasing $\gamma$ due to limitation of column efficiency. This optimisation problem asserts that SMBR performance can be improved if design parameters are also optimised along with operating parameters. A high value of both yield and purity were obtained when column length was also introduced as a decision variable.

\subsection{Case 2.2 Maximisation of Purity and Minimisation of Desorbent Consumption}

The objective functions, constraints and decision variables for this problem are the same as those of Case 1.2, with the addition of another decision variable; column length $\left[0.2(\mathrm{~m}) \leq \mathrm{L}_{\mathrm{col}} \leq 0.5(\mathrm{~m})\right]$. The Pareto optimal solutions are shown in Figure 7. Figure 7 shows the relation between $\gamma$ and purity. At lower values of $\gamma$, a linear relation exists with purity. However, after that, the graph becomes exponential; indicating that a slight increase in purity would require a very high desorbent consumption, just as in case 1.2. Hence, $\gamma$ 
should be just high enough above a threshold value ( $\approx 2$ in this case). Further increase is not necessary.

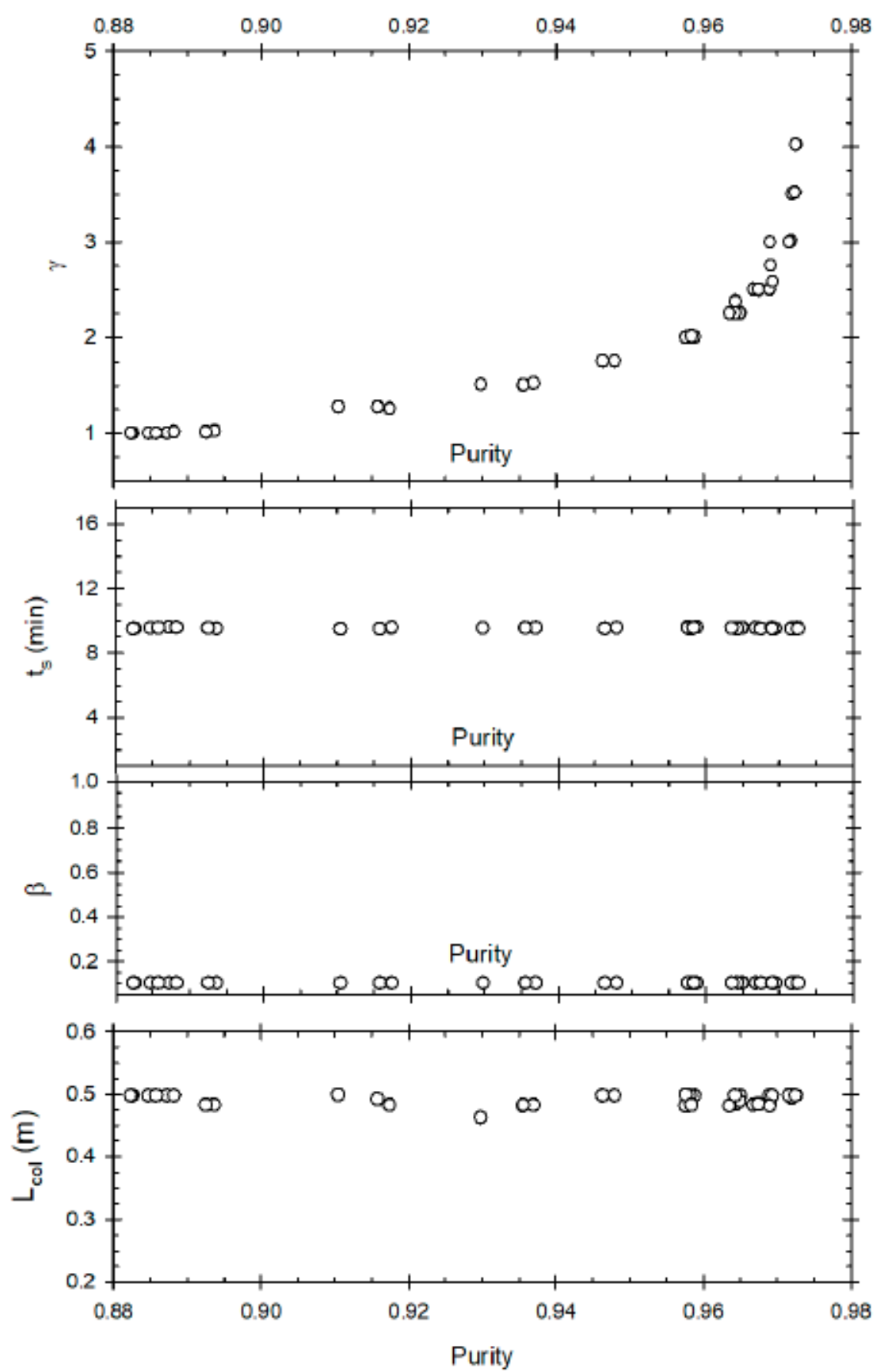

Figure 7. Case 2.2 Design-stage Optimization. Maximization of Purity and minimization of desorbent consumption. Pareto optimal solutions and corresponding operating variables.

Figure 7 shows the dependence of purity on raffinate flow rate.

$\beta$ is constant at a low value $(\approx 0.1)$. Hence purity is not sensitive to it when column length is a decision variable and minimisation of desorbent consumption is an objective. The same trend is shown by switch time; it is constant at around 9 min (Figure 7). The dependence of purity on column length is uniform, showing requirement of a high column length for high purity (Figure 7). 


\section{Conclusions}

Multi-objective optimisation studies were carried out on the performance of a reactive SMB for synthesis of biodiesel. The NSGA algorithm was used to obtain the Pareto optimal solutions. Optimisation of both existing set-up and design-stage were studied. Two multi-objective optimisation problems were solved involving two objective functions for each mode of operation. Simultaneous maximisation of yield and purity as well as maximisation of purity and minimisation of desorbent consumption were considered as objective functions. It was observed that a yield and purity of above $90 \%$ can be achieved by optimizing both operating and design stage parameters. This study extols the usefulness of multi-objective optimisation for improvement of design and operation of reactive SMB system for its practical application and successful implementation on industrial scale.

Author Contributions: Conceptualization, Methodology, Software; Validation, Formal Analysis, Investigation, Data Curation, Writing Original Draft, Visualization: N.M.R., Resources, WritingReview and editing, Supervision, Project Administration, Funding Acquisition: A.K.R. Both authors have read and agreed to the published version of the manuscript.

Funding: Authors acknowledge funding received from Natural Sciences and Engineering Research Council (NSERC) of Canada under grant number R3839A44.

Institutional Review Board Statement: The study was conducted according to the guidelines of the University of Western Ontario. Ethical review and approval were waived for this study, due to the work being exclusively computational.

Informed Consent Statement: Not applicable.

Data Availability Statement: Data available upon request to the corresponding author.

Conflicts of Interest: The authors declare no conflict of interest.

\section{References}

1. Ray, A.K.; Carr, R.W.; Aris, R. The simulated countercurrent moving bed chromatographic reactor: A novel reactor-Separator. Chem. Eng. Sci. 1994, 49, 469-480. [CrossRef]

2. Ray, A.; Carr, R.W. Experimental study of a laboratory-scale simulated countercurrent moving bed chromatographic reactor. Chem. Eng. Sci. 1995, 50, 2195-2202. [CrossRef]

3. Yu, W.; Hidajat, K.; Ray, A.K. Application of multi-objective optimization in the design and operation of reactive SMB and its experimental verification. Ind. Eng. Chem. Res. 2003, 42, 6823-6831. [CrossRef]

4. Ray, N.M.; Ray, A.K. Modelling, simulation, and experimental study of a simulated moving bed reactor for the synthesis of biodiesel. Can. J. Chem. Eng. 2016, 94, 913-923. [CrossRef]

5. Bhaskar, V.; Gupta, S.K.; Ray, A.K. Applications of Multi-objective Optimization in Chemical Engineering. Rev. Chem. Eng. 2000, 16, 1. [CrossRef]

6. Tarafder, A.; Rangaiah, G.P.; Ray, A.K. A study of neighbourhood multi-modal multi-objective (nM3O) solutions in chemical process optimization. Comput. Chem. Eng. 2007, 31, 1257-1271. [CrossRef]

7. Bhaskar, V.; Gupta, S.K.; Ray, A.K. Multi-objective optimization of an industrial wiped film poly(ethylene terephthalate) reactor. AIChE J. 2000, 46, 1046. [CrossRef]

8. Zhou, F.; Gupta, S.K.; Ray, A.K. Multi-objective optimization of the continuous casting process for poly(methyl methacrylate) using adapted genetic algorithm. J. Appl. Polym. Sci. 2000, 78, 1439. [CrossRef]

9. Rajesh, J.K.; Gupta, S.K.; Rangaiah, G.P.; Ray, A.K. Multi-objective optimization of steam reformer performance using genetic algorithm. Ind. Eng. Chem. Res. 2000, 39, 706. [CrossRef]

10. Yuen, C.C.; Aatmeeyata Gupta, S.K.; Ray, A.K. Multi-objective optimization of membrane separation modules using genetic algorithm. J. Membr. Sci. 2000, 176, 177. [CrossRef]

11. Rajesh, J.; Gupta, S.; Rangaiah, G.; Ray, A. Multi-objective optimization of industrial hydrogen plants. Chem. Eng. Sci. 2001, 56, 999-1010. [CrossRef]

12. Tarafder, A.; Lee BC, S.; Ray, A.K.; Rangaiah, G.P. Multi-objective Optimization of an Industrial Ethylene Reactor using a Non-dominated Sorting Genetic Algorithm. Ind. Eng. Chem. Res. 2005, 44, 124-141. [CrossRef]

13. Tarafder, A.; Rangaiah, G.P.; Ray, A.K. Multi-objective Optimization of an Industrial Styrene Monomer Manufacturing Process. Chem. Eng. Sci. 2005, 60, 347-363. [CrossRef]

14. Bhutani, N.; Rangaiah, G.P.; Ray, A.K. Modeling, simulation and multi-objective optimization of industrial hydrocracking reactor. Ind. Eng. Chem. Res. 2006, 45, 1354-1372. [CrossRef] 
15. Agrawal, N.; Gupta, S.K.; Ray, A.K. Multi-objective Optimization of the Operation of an Industrial Low-Density Polyethylene Tubular Reactor using Jumping Gene Adaptations. Ind. Eng. Chem. Res. 2006, 45, 3182-3199. [CrossRef]

16. Lee, F.C.; Rangaiah, G.P.; Ray, A. Multi-objective optimization of an industrial penicillin V bioreactor train using non-dominated sorting genetic algorithm. Biotechnol. Bioeng. 2007, 98, 586-598. [CrossRef] [PubMed]

17. Mazumder, J.; Zhu, J.; Bassi, A.S.; Ray, A.K. Multiobjective optimization of the operation of a liquid-solid circulating fluidized bed ion-exchange system for continuous protein recovery. Biotechnol. Bioeng. 2009, 103, 873-890. [CrossRef]

18. Kundu, P.; Zhang, Y.; Ray, A.K. Multi-objective optimization of oxidative coupling of methane in a simulated moving reactor. Chem. Eng. Sci. 2009, 64, 4137-4149. [CrossRef]

19. Quddus, R.; Ray, A.K. Modelling and Multi-objective optimization of oxidative coupling of methane in a catalytic membrane reactor. Ind. Eng. Chem. Res. 2010, 49, 6469-6481. [CrossRef]

20. Quddus, M.R.; Zhang, Y.; Ray, A.K. Multi-objective Optimization of a Porous Ceramic Membrane Reactor for Oxidative Coupling of Methane. Ind. Eng. Chem. Res. 2010, 49, 6469-6481. [CrossRef]

21. Zhang, Z.; Hidajat, K.; Ray, A.K. Multi-objective optimization of simulated moving bed reactor for MTBE synthesis. Ind. Eng. Chem. Res. 2002, 41, 3213-3232. [CrossRef]

22. Zhang, Z.; Hidajat, K.; Ray, A.K.; Morbidelli, M. Multi-objective optimization of simulated moving bed system and Varicol process for chiral separation. AIChE J. 2002, 48, 2800-2816. [CrossRef]

23. Subramani, H.J.; Hidajat, K.; Ray, A.K. Optimization of reactive SMB and Varicol systems. Comput. Chem. Eng. 2003, $27,1883-1901$. [CrossRef]

24. Zhang, Y.; Hidajat, K.; Ray, A.K. Optimal design and operation of SMB bioreactor: Production of high fructose syrup by isomerization of glucose. Biochem. Eng. J. 2004, 21, 111-121. [CrossRef]

25. Kurup, S.A.; Subramani, H.J.; Hidajat, K.; Ray, A.K. Optimization of Reactive SMB and Varicol for Sucrose Inversion. Chem. Eng. J. 2005, 108, 19-33. [CrossRef]

26. Kurup, A.S.; Hidajat, K.; Ray, A.K. Comparative Study of Modified Simulated Moving Bed Systems at Optimal Conditions for the Separation of Ternary Mixtures of Xylene Isomers. Ind. Eng. Chem. Res. 2006, 45, 6251-6265. [CrossRef]

27. Kurup, A.S.; Hidajat, K.; Ray, A.K. Optimal operation of a Pseudo-SMB process for ternary separation under non-ideal conditions. Sep. Purif. Technol. 2006, 51, 387-403. [CrossRef]

28. Zhang, Y.; Hidajat, K.; Ray, A.K. Enantioseparation of Racemic Pindolol on Chira-AGP Stationary Phase by SMB and Varicol Processes. Chem. Eng. Sci. 2007, 62, 1364-1375. [CrossRef]

29. Zhang, Y.; Hidajat, K.; Ray, A.K. Modified reactive SMB for production of high concentrated fructose syrup by isomerization of glucose to fructose. Biochem. Eng. J. 2007, 35, 341-351. [CrossRef]

30. Yan, Z.; Hidajat, K.; Ray, A.K. Multiobjective optimization of SMB and Varicol processes for Enantio-separation of racemic Pindolol. Sep. Purif. Technol. 2009, 65, 311-321.

31. Nandasana, A.D.; Ray, A.K.; Gupta, S.K. Applications of the Non-Dominated Sorting Genetic Algorithm (NSGA) in Chemical Reaction Engineering Applications of the Non-Dominated Sorting Genetic Algorithm (NSGA) in Chemical Reaction Engineering. Int. J. Chem. React. Eng. 2003, 1, 1-20.

32. Kasat, R.B.; Ray, A.K.; Gupta, S.K. Applications of Genetic Algorithm in Polymer Science and Engineering. Mater. Manuf. Process. 2003, 18, 523-532. [CrossRef]

33. Taylor, C.E. Adaptation in Natural and Artificial Systems: An Introductory Analysis with Applications to Biology, Control, and Artificial Intelligence. Complex Adaptive Systems. John H. Holland. Q. Rev. Biol. 1994, 69, 88-89. [CrossRef]

34. Srinivas, N.; Deb, K. Muiltiobjective Optimization Using Nondominated Sorting in Genetic Algorithms. Evol. Comput. 1994, 2, 221-248. [CrossRef]

35. Petroulas, T.; Aris, R.; Carr, R. Analysis and performance of a countercurrent moving-bed chromatographic reactor. Chem. Eng. Sci. 1985, 40, 2233-2240. [CrossRef]

36. Fish, B.; Carr, R.W.; Aris, R. The continuous countercurrent moving bed chromatographic reactor. Chem. Eng. Sci. 1986, 41, 661-668. [CrossRef]

37. Ray, A.; Tonkovich, A.; Aris, R.; Carr, R. The simulated countercurrent moving bed chromatographic reactor. Chem. Eng. Sci. 1990, 45, 2431-2437. [CrossRef]

38. Hashimoto, K.; Adachi, S.; Noujima, H.; Maruyama, A. Models for separation of glucose-frucose mixture using a simulated moving bed adsorber. J. Chem. Eng. Jpn. 1983, 16, 400. [CrossRef]

39. Ruthven, D.M. The axial dispersed plug flow model for continuous counter-current adsorbers. Can. J. Chem. Eng. 1983, 61, 881-883. [CrossRef]

40. Mazzotti, M.; Kruglov, A.; Neri, B.; Gelosa, D.; Morbidelli, M. A continuous chromatographic reactor: SMBR. Chem. Eng. Sci. 1996, 51, 1827-1836. [CrossRef]

41. Atadashi, I.; Aroua, M.; Aziz, A.A. High quality biodiesel and its diesel engine application: A review. Renew. Sustain. Energy Rev. 2010, 14, 1999-2008. [CrossRef]

42. Canakci, M.; Van Gerpen, J.H. The Performance and Emissions of a Diesel Engine Fueled with Biodiesel from Yellow Grease and Soybean Oil. Am. Soc. Agric. Biol. Eng. 2001, 0300,1-17. 